\title{
Educação na Modernidade Líquida: Entre Tensões e Desafios
}

\author{
Cássia Cristina Furlan ${ }^{1}$, \\ ELIANe Rose MAIO ${ }^{2}$
}

\begin{abstract}
Resumo
Este trabalho tem por objetivo compreender as crises paradigmáticas que se multiplicam no campo da educação e na sociedade em geral, refletindo diretamente as influências dessa crise no contexto das teorias pedagógicas na contemporaneidade. Problematizamos aspectos do pensamento pós-moderno e diversos/as autores/as que privilegiam mudanças de perspectiva acerca dos postulados da modernidade, como Bauman (2001; 2010; 2013), Harvey (2012), Santos (2007), Lyotard (1988) e alguns/mas outros/as que darão subsídio às nossas reflexões. Tais prerrogativas se sustentam na atual crise societária que tem propiciado o questionamento das metanarrativas modernas e seus pilares de sustentação diante das transformações ocorridas na denominada Modernidade Líquida.
\end{abstract}

Palavras-chave: Educação; Modernidade líquida; Teorias pedagógicas; Pósmoderno.

\section{Education in Liquid Modernity: Between Tensions And Challenges}

\footnotetext{
Abstract

This study aims to understand the paradigmatic crises that are multiplying in education and in society in general, directly reflecting the influence of the crisis in

1 Doutoranda em Educação na Universidade Estadual de Maringá (UEM), Brasil. cassiacfurlan@gmail.com

2 Professora-doutora do Departamento de Teoria e Prática da Educação da Universidade Estadual de Maringá (UEM), Brasil. elianerosemaio@yahoo.com.br
} 
the context of pedagogical theories in the contemporary world. We problematize aspects of postmodern thought and several authors who favor changes of perspective about the tenets of modernity, as Bauman (2001; 2010; 2013), Harvey (2012), Santos (2007), Lyotard (1988) and some others who will subsidise our reflections. Such prerogatives are sustained in the current social crisis that has allowed the questioning of modern metanarratives and its supporting pillars in face of changes occurred in the denominated Liquid Modernity.

Keywords: Education; Liquid modernity; Pedagogical theories; Postmodern.

\section{INTRODUÇÃo}

As crises e evidências paradigmáticas na e da educação têm extensas relações com as crises paradigmáticas mais profundas no campo do sistema capitalista. Se, por um lado, esses paradigmas ${ }^{3}$ têm muitos aspectos em comum, uma vez solidificados pelos signos modernos, por outro lado, eles possuem uma história particular porque tratam de questões específicas, cujas crises provavelmente assolam os mais diversos setores da sociedade.

$\mathrm{Na}$ concepção de Bauman (2013), a crise da educação contemporânea é muito peculiar porque, provavelmente pela primeira vez na história moderna, percebemos que as diferenças entre os seres humanos e a falta de um modelo universal vieram para ficar. Nessa perspectiva, este trabalho sugere buscarmos a compreensão das intensas crises que se multiplicam no campo da educação, no que se refere à construção de diferentes paradigmas que estão propiciando posturas distintas ante as discussões acerca das tendências pedagógicas na contemporaneidade. Sendo assim, visamos à apresentação de aspectos do pensamento pós-moderno que exercem influência na educação contemporânea, objetivando, também, apresentar autores/ teorias que privilegiam uma mudança de pensamento com relação aos

3 Para Morin (1988), paradigma assume a forma de um modelo conceitual que dirige todos os discursos. Quando falamos de crises paradigmáticas no contexto da pós-modernidade, nos referimos às brechas e rupturas no discurso moderno apoiado em suas metanarrativas que já não mais se sustentam. O velho paradigma reduziu-se a migalhas, mas o novo ainda não está construído. 
postulados da modernidade, visto que alguns não mais se sustentam na atual crise societária em que estamos inseridos/as.

Para tanto, apresentamos alguns pontos importantes no tocante às mudanças de paradigmas Modernidade/Pós-Modernidade, ampliando as discussões para a educação, dialogando com autores/ as (BAUMAN, 2001; 2010; 2013; HARVEY, 2012; LYOTARD, 1988; MOREIRA, TADEU, 2011, SANTOS, 2007; SILVA, 2011; dentre outros/ as) que serão referências nesse embate. Tais autores nos proporcionam a reflexão acerca da fragmentação ocasionada no contexto pósmoderno, ensejando a análise das possibilidades e provisoriedades da perspectiva supracitada. Bauman (1997) afirma que a perspectiva pósmoderna-ou modernidade líquida, como ele prefere chamar-significa sobretudo o rasgamento da máscara das ilusões e o reconhecimento de certas pretensões como falsas e de certos objetivos como inatingíveis.

\section{Características Históricas e Culturais da Sociedade e Educação na Contemporaneidade}

Estamos diante de um cenário de fragmentação teórica, social, econômica, cultural que, para Lima (2010, p. 2), repercute sobre o importante cenário educacional, que é "[...] a destituição dos alicerces de estabilidade do discurso pedagógico que sustentam práticas educacionais escolares, sejam elas consideradas progressistas ou conservadoras".

Retomando as leituras de Bauman (ALMEIDA; GOMES; BRACHT, 2009, p. 17), arriscamo-nos a dizer que o conceito de ordem foi eleito como chave de leitura para a compreensão da civilização moderna. "A sociologia de Bauman demonstra que o sonho moderno de uma sociedade ordenada acabou (re)produzindo o seu contrário, quer dizer, mais desordem, mais caos ou, conforme a expressão que ele empregou para caracterizar essa tendência, mais ambivalência", 
ou seja, a modernidade, ao eleger a ordem como sua grande utopia, acabou por produzir suas próprias distopias, também no campo da educação.

Segundo Bauman (1999), a linguagem esforça-se em sustentar a ordem e negar ou suprimir o acaso e a contingência. Entretanto, a situação se torna ambivalente quando os instrumentos linguísticos de estruturação se mostram inadequados, não é mais possível classificar/nomear, pois a situação já não pertence somente às classes linguisticamente discriminadas, mas pode recair sobre várias delas ao mesmo tempo. A ambivalência é a impossibilidade de viver sob alicerces estáveis, sob condições de reconhecida contingência.

$\mathrm{Na}$ transição para o século XXI, o autor destaca o novo aspecto da condição moderna, desta vez baseado na metáfora da liquidez ${ }^{4}$. Nesse sentido, diferencia a modernidade vivida por nossos antepassados - a Modernidade Sólida ${ }^{5}$, e uma modernidade referindose ao contemporâneo, ou seja, a Modernidade Líquida ${ }^{6}$, sem, no entanto, trazer qualquer noção de ruptura completa entre essas duas modernidades.

Para Bauman (2013, p. 22), se a vida pré-moderna presumia a duração de todas as coisas, exceto a vida mortal, a vida líquidomoderna pressupõe a transitoriedade universal, a fluidez instantânea

4 Bauman busca em Marx, no Manifesto Comunista, a inspiração para a criação dessas metáforas da liquidez. É de Marx e Engels a famosa sentença segundo a qual, na modernidade, "tudo que é sólido se desmancha no ar" (ALMEIDA; GOMES; BRACHT, 2009).

5 Luiz Felipe Pondé (2011), em "A invenção do contemporâneo: o diagnóstico de Zygmunt Bauman para a Pós-Modernidade", a chamada modernidade (Modernidade Sólida para Bauman) começou mais ou menos em 1500, com a crença na transformação do mundo através da ciência e da racionalidade, atingindo sua maturidade no século XIX, pelo fato de os intelectuais da época acreditarem possuir a fórmula para a explicação de todas as coisas na sociedade. A partir do século XX, a modernidade começa a dar sinais de crise.

6 A Pós-Modernidade (Modernidade Líquida) pressupõe que as crenças da modernidade já não dão conta de explicar as relações, não conseguem resolver os problemas presentes na sociedade. As fórmulas para a explicação da sociedade já não respondem às necessidades. A consciência pós-moderna é a consciência de que a modernidade fracassou nas utopias que ela prometeu (PONDÉ, 2011). 
das coisas, dos conhecimentos, das relações humanas. "Tudo nasce com a marca da morte iminente e emerge da linha de produção com o "prazo de validade' impresso ou presumido".

Não foi somente no âmbito teórico-científico que as crises foram evidenciadas. Toda a nossa cultura e sociedade, de forma geral, em seu sistema de valores, encontra-se em crise, corporificada por acontecimentos como a probabilidade de ocorrência de uma guerra nuclear; a grave deterioração do meio ambiente; a comercialização de produtos químicos altamente tóxicos a nossa saúde; doenças nutricionais, infecciosas, crônicas e degenerativas, em proliferação nunca vista antes; patologias sociais; anomalias econômicas; dentre outros (CAPRA, 1982 apud FRANÇA, 2009, p. 44).

Essas crises cíclicas produzidas e reproduzidas pelas mudanças culturais na contemporaneidade têm lançado discussões acerca das transformações paradigmáticas a que Bauman (2001) faz referência ao postular a passagem da Modernidade Sólida para a Modernidade Líquida. Outros/as autores/as (HARVEY, 2012; HUTCHEON, 2002; MCLAREN, 1993; LYOTARD, 1988; SANTOS, 2007, dentre outros/ as) propõem discussões relativas à "Pós-Modernidade", à "Segunda Modernidade" ${ }^{\prime 7}$, ou outros termos similares, mostrando que o movimento de mudança chegou ao seu 'limite natural'.

Harvey (2012, p. 19) propõe que talvez só haja concordância em afirmar que "o 'pós-modernismo's ${ }^{8}$ representa alguma espécie de reação ao 'modernismo' ou de afastamento dele. Como o sentido

7 Bauman (2001, p. 12) apresenta as discussões de Ulrich Beck, que alguns anos antes cunhara o termo "Segunda Modernidade" para controlar a fase marcada pela modernidade "voltando-se sobre si mesma", a era da assim chamada "modernização da modernidade".

8 Bauman (2011) propõe o afastamento ao termo pós-modernidade, por ser amplamente empregado como pós-modernismo, que para ele, como todos os ismos, se referia a um projeto ou a uma atitude. Para ele, falar em pós-modernidade, diferente de pós-modernismo, seria referir-se à qualidade de um tipo determinado de sociedade que pareceria ser a nossa, embora diferente da dos nossos pais. Ao confundirem-no com um autor pós-moderno, retira a terminologia, afirmando ser um sociólogo dos tempos pós-modernos (da pós-modernidade) e não um sociólogo pós-moderno. Prefere, portanto, adotar o termo Modernidade Líquida. 
de modernismo também é muito confuso, a reação ou afastamento conhecido como 'pós-modernismo' o é duplamente". O pósmodernismo assinala a morte das metanarrativas (HARVEY, 2012; HUTCHEON, 2002; LYOTARD, 1988), cuja função era fundamentar e legitimar uma história humana 'universal'.

Acresce que o pós-modernismo é hoje a designação usada para caracterizar enorme diversidade de conhecimentos, da epistemologia à política, à cultura e à arte e, portanto, confunde mais do que esclarece e não representa uma teoria coerente e unificada, mas um conjunto variado de perspectivas (SANTOS, 2007; SILVA, 2011). Esse episódio se comprova pelo fato de a reação crítica ao movimento vir tanto dos setores da direita conservadora como dos setores marxistas mais ortodoxos (SANTOS, 2007). Nesse sentido, a Pós-Modernidade representa uma ruptura cultural e epistemológica com o período moderno que fracassou na tentativa de construir sujeitos autônomos capazes de superar a sua alienação (McLAREN, 1993 apud GOERGEN, 2012).

É razoável postular a existência de uma cultura pós-moderna amplamente difundida (individualismo, desengajamento, consumo como eixo das relações sociais, crise do político, descrença no universal), coexistindo em um tempo que já não pode ser considerado moderno, visto que, como supõe Bauman (2011), a sociedade moderna tinha uma sede insaciável de normas que não deram conta de ordenar as relações e se tornaram progressivamente ambivalentes. Nesse contexto, não temos mais um terreno firme, um destino exato. Vivemos a Modernidade Líquida, pois para o autor, "somos tão modernos como nunca, 'modernizando' de modo obsessivo tudo aquilo que tocamos. Um dilema, portanto: o mesmo, embora diferente, a descontinuidade na continuidade" (BAUMAN, 2011, p. 83). Ao se referir a Lyotard, o autor concorda com o fato de que não se pode ser realmente moderno sem antes ser pós-moderno. Portanto, “a pós-modernidade 
é a modernidade reconciliada com sua própria impossibilidade - e decidida, por bem ou por mal, a viver com ela" (BAUMAN, 1999, p. 110).

\section{Sociedade de Consumidores/As}

Analisando a ocorrência de mudanças no tocante à sociedade, Bauman (2010) expõe os nós cruciais que estão entrelaçados ao sistema capitalista, de modo a reforçar a transição paradigmática para uma sociedade pós-moderna, no que se refere à fluidez dos laços, sentidos e explicações modernas, às reinterpretações culturais, sociais e econômicas advindas da transição entre modelos de produção capitalista e entre formas de exploração capitalista, relativas, por exemplo, à exacerbada preocupação com a criação e manutenção de consumidores, desde a mais tenra idade.

Para o autor, o "[...] capitalismo se destaca por criar problemas, e não por solucioná-los" (BAUMAN, 2010, p. 7). Uma cultura foi instaurada, de modo que toda uma nova geração está circundada por uma cultura 'agorista', promovendo o culto à novidade, à contingência aleatória, ao consumo incansável e, ao mesmo tempo, insaciável. Os discursos fragmentários ameaçam se tornar hegemônicos, criando narrativas desordenadas, distribuídas a uma velocidade cada vez maior, tendo consequências imediatas na maneira como nos relacionamos com os conhecimentos, o trabalho e o estilo de vida num sentido amplo (BAUMAN, 2013).

Bauman (2013) afirma que estamos diante de um mundo fluido e liquidificado, o qual supõe que devamos evitar a transformação das coisas em hábitos. Essa racionalidade impõe uma cultura do desengajamento, da descontinuidade e do esquecimento. O incentivo está voltado para o consumo imediato com o máximo impacto e obsolescência instantânea. Entretanto, para o autor, os/as 
consumidores/as excluídos/as, não comprar significa não somente a falta de prazer, mas a falta de dignidade humana.

Perante o cenário de consumidores/as ávidos/as por novidades, há um enfraquecimento e deterioração dos vínculos humanos. Esses acontecimentos, reafirmados por valores capitalistas, refletem suas concepções no tocante à educação. No final dos anos 50 , com as mudanças advindas da sociedade capitalista, para Moreira e Tadeu (2011), o sentimento de crise acabou por instalar-se na sociedade: foi uma crise que chegou a envolver mesmo o significado e o sentido da vida. Criticaram-se os discursos pedagógicos, o papel da escola; questionavam-se as diferentes tendências. Entretanto, não se questionava mais profundamente a sociedade capitalista que se consolidara, nem o papel da escola na preservação dessa sociedade cada vez mais voltada para o consumo. Desse modo, muitas foram as teorias críticas (Neomarxismo, teoria crítica da Escola de Frankfurt, as teorias da reprodução, fenomenologia, psicanálise, entre outras) que começaram a servir de referencial a diversos/as teóricos/as (MOREIRA; TADEU, 2011).

Assim, como apresentam os autores Moreira e Tadeu (2011), tem havido importantes modificações nas formas de conceber o conhecimento e a linguagem. O chamado movimento pós-moderno vem examinar as concepções que constituem o núcleo de nossas noções de educação e currículo. "A contestação pós-moderna coloca em questão o papel das 'grandes narrativas' e da noção de razão e racionalidade que têm sido centrais ao projeto cognitivo moderno $\mathrm{e}$, derivadamente, àquilo que entendemos como conhecimento educacional" (MOREIRA; TADEU, 2011, p. 43-44).

O cenário contemporâneo nos coloca diante da incapacidade de obter respostas absolutas para fundamentar as questões relativas à vida, em uma conjuntura de declínio dos modelos de vida ética. Para o contexto educacional, esse cenário não é diferente, desencadeando 
dificuldades para sustentar escolhas teóricas e práticas que ancorarão a prática docente (LIMA, 2010). Com o modelo de sociedade visualizado a partir do século XX e início do século XXI, já não podemos sustentar as noções construídas sob o espectro da modernidade, pois esse momento denominado "pós-moderno" desconfia profundamente dos impulsos emancipadores e libertadores da pedagogia moderna.

Em sociedades com economias supostamente qualificadas pelo conhecimento e embasadas na informação, como as sociedades ocidentais, com sucesso econômico orientado pela educação, percebemos que o conhecimento já não é uma garantia de sucesso, a educação já não provê esse conhecimento que, consequentemente, geraria uma mobilidade social ascendente. O mercado de trabalho para portadores de diploma está encolhendo. Bauman (2010; 2013) afirma que estamos num momento em que talvez haja uma primeira geração realmente global, a geração "Ni-Ni" (nem emprego nem educação). O consumismo de hoje consiste em acumular objetos, com descartabilidade total. Sendo assim, por que o 'pacote de conhecimentos' adquiridos na universidade seria diferente? Portanto, como qualquer produto nas prateleiras à venda, a educação também passa a ser um 'produto', mas não um 'produto' feito para ser apropriado e conservado, como se acreditava no auge da Modernidade Sólida, e sim consumido e descartado, à medida das necessidades que o mercado impõe, e essas relações com a educação não depõem a favor da educação institucionalizada, nos moldes atuais (BAUMAN, 2010).

A educação, inserida no contexto da Modernidade Líquida, segue o modelo do mercado, ou seja, a antiga sabedoria perdeu seu valor pragmático e as pessoas preocupadas com a aprendizagem e sua promoção tiveram que mudar seu foco de atenção. É preciso desenvolver o talento de aprender depressa e a capacidade de esquecer instantaneamente o que foi aprendido. As informações envelhecem rapidamente, o conhecimento torna-se eminentemente descartável. 
Sendo assim, a garantia de sucesso é não deixar passar o momento em que o conhecimento adquirido precisa ser esquecido, substituído (BAUMAN, 2010; 2013).

Algumas correntes modernas da educação buscam rearticular seus discursos face às transformações que marcam a contemporaneidade. Estas, como apresenta Libâneo (2005), podem fazer parte de esforços teóricos de releitura das teorias modernas, ou afiliar-se explicitamente ao pensamento pós-moderno focado ou não na escola e no trabalho docente.

Entretanto, apesar dos esforços em denominar teorias e correntes pedagógicas no campo da educação, esse momento pós-moderno parece representar a 'não-garantia' de que as suas consequências serão duradouras, ou mesmo que terão um objetivo claro. Sendo assim, como no campo da educação seria diferente? A ausência de certezas atinge todos os campos do conhecimento. Com isso, há algumas formulações teóricas sobre a educação e suas teorias, mas para Libâneo (2005), essas correntes denominadas "pós-modernas" não se sentem confortáveis em se autodenominar Pedagogias, assim como também recusam classificações. Contudo, mesmo que pela negação, podem ser consideradas "pedagogias" já que influenciam as práticas docentes. Se pensarmos nas diversas teorizações que perpassam o desenvolvimento da pedagogia, teremos inúmeras classificações contemporâneas, mesmo que haja discordância entre inúmeros/as teóricos/as na dinâmica da educação. 


\section{Educação nos Contextos de Transiçãó}

A história da educação conheceu muitos momentos críticos evidenciadores de que premissas postuladas e aparentemente confiáveis não davam conta da realidade e exigiam revisões e reformas. Todavia, a crise atual parece estar se diferenciando daquela do passado, pois os desafios do presente desferem duros golpes contra a própria essência da ideia de educação, tal como ela se formou nos primórdios da civilização. No mundo líquido-moderno, a solidez das coisas, assim como a solidez dos vínculos humanos, é vista como ameaça diante de uma sociedade de consumidores (BAUMAN, 2010).

Bauman (2009) afirma que a educação e a aprendizagem, para serem úteis no ambiente líquido-moderno, devem ser contínuas e durar toda a vida, sendo impensáveis de qualquer outro modo que não seja aquele contínuo e perpetuamente incompleto. Nas concepções líquido-modernas não existe uma cultura da sociedade, unitária, homogênea e universalmente aceita e praticada. Em vez disso, para Moreira e Tadeu (2011), a cultura é vista como um campo e terreno de luta, onde se enfrentam diferentes e conflitantes concepções de vida social.

Ghiraldelli Junior (2000) considera que as pessoas do século XIX e XX no Ocidente assistiram a três grandes revoluções ${ }^{10} \mathrm{em}$ teorias educacionais, as quais podemos chamar de revoluções modernas. E, na transição do século XX para o século XXI, estamos a assistir a uma quarta revolução, denominada pós-moderna. As três primeiras revoluções, segundo o autor, têm seus melhores representantes em

9 Mesmo diante da intensa negação de diversos/as teóricos na academia, em relação à temática da Pós-Modernidade, não podemos negar que esse é um momento histórico, e mesmo que haja diversas denominações - como Modernidade Líquida, Pós-Modernidade, Segunda Modernidade, Contemporaneidade - perpassam um tempo histórico de intensas modificações nos referenciais educacionais, políticos, econômicos, culturais e sociais. Sendo assim, não podemos ignorar esse "novo" tempo, como suas dinâmicas fluidas e ambivalentes.

10 Não nos aprofundamos nos "porquês" da escolha desses autores/teorias na classificação das revoluções realizadas pelo autor. Para mais informações, consultar Ghiraldelli Junior (2000). 
Herbart, Dewey e Paulo Freire. A quarta revolução apresenta autores como Richard Rorty e Donald Davidson.

Essa nova filosofia da educação em nada solapa os ideais das filosofias da educação modernas, pelo contrário, ela os potencializa. [...] Quem faz metáforas ${ }^{11}$ em prol da criação de novos direitos está, certamente, colaborando com a ideia humanista de que a educação é aquisição de autodeterminação, como em Herbart. Também está favorecendo a diversidade e a liberdade e, portanto, está se alinhando com Dewey (ou hoje, com Habermas), na valorização da democracia. E pode fornecer "autoridade semântica" para os grupos oprimidos se redescreverem e assim ganhar vez e voz na sociedade na medida em que possam colocar seus vocabulários alternativos, seus jogos de linguagem - até então, secundarizados ou mesmo considerados loucos -, como elementos também contáveis, na sociedade. Com isso, colabora-se com Paulo Freire, na luta por uma educação em favor do oprimido pelo fim da opressão. A "teoria educacional pós-moderna", nessa filosofia da educação, é a busca de realização dos melhores ideais modernos (GHIRALDELLI JUNIOR, 2000, p. 62).

Sendo assim, as revoluções do passado não perderam importância diante da revolução que está ocorrendo agora. Pertencem ao passado num sentido cronológico e não valorativo, mas perpassam as construções teóricas contemporâneas na educação.

Para Silva (2011), tornou-se lugar-comum destacar a diversidade das formas culturais do mundo contemporâneo. É um fato paradoxal, contudo, que essa suposta diversidade coexista com fenômenos igualmente surpreendentes de homogeneização cultural. Inicialmente, para o autor, a teorização crítica sobre educação e currículo concentrava-se na análise da dinâmica de classe no processo de reprodução cultural da desigualdade e das relações hierárquicas na

11 O conceito de metáfora é fundamental no entendimento das arguições do autor (Donald Davidson). A metáfora, para Davidson, não pode ser parafraseada. E, se quisermos explicála, certamente estaremos sujeitos a fazer alguma construção teórica sofrível, de gosto duvidoso. A metáfora vai se definir como elemento da linguagem através do seu uso - por nós (GHIRALDELLI JUNIOR, 2000). 
sociedade capitalista. Mas as mudanças paradigmáticas no campo das teorizações culturais e a crescente visibilidade de alguns movimentos forçaram uma mudança de perspectiva na produção do conhecimento educacional.

As teorizações feministas são um exemplo da visibilidade do movimento nas mudanças de perspectiva da educação, concedendo crescente importância ao papel do gênero na produção da desigualdade (SILVA, 2011).

[...] a pedagogia feminista preocupou-se, sobretudo, em desenvolver formas de ensino que refletissem os valores feministas e que pudessem formar um contraponto às práticas pedagógicas tradicionais, que eram consideradas como expressão dos valores masculinos e patriarcais (SILVA, 2011, p. 96).

Nas discussões do quesito construção da ciência, Guacira Lopes Louro (2007) formula uma reivindicação quanto à constituição das representações científicas. A autora afirma haver uma história que ganhou legitimidade e universalidade na construção de uma epistemologia científica.

Esta Ciência, escrita com maiúsculas, fala por todos e de todos, já que foi pensada, conduzida e instituída a partir dos interesses e das questões daqueles cujas vozes pretenderam (e pretendem) representar toda a humanidade. Ela foi feita pelos homens - os homens brancos ocidentais de classe dominante - os quais, supostamente, fizeram as perguntas e deram as respostas que interessavam a todas as pessoas. Possuidores de alguma capacidade "extraordinária", eles sempre "souberam" o que era importante em geral (LOURO, 2007, p. 143).

Nesta perspectiva, outras leituras e soluções para os impasses de um tempo cujas teorias se querem universalizantes podem estar no aparecimento de vozes antes silenciadas, desafiando a própria forma de fazer ciência até então hegemônica. As feministas, assim como outros movimentos num tempo pós-moderno, questionaram 
as insuficiências ou incompletudes nos paradigmas teóricometodológicos, abalando radicalmente esses paradigmas. Na vertente dos Estudos Feministas, não há possibilidade, nem pretensão do estabelecimento de conceitos teórico-metodológicos assentados, estáveis, mais ou menos indiscutíveis e aceitos por todos/as. O objetivo dessas teorias é operar com categorias analíticas instáveis, é movimentar-se em meio a um campo teórico que está em contínua construção, acolhendo a crítica como parte da sua construção (LOURO, 2007). As formulações pedagógicas erigidas na perspectiva feminista apoiam-se no reconhecimento das desigualdades vividas no interior das instituições escolares, propondo estratégias, procedimentos e disposições para romper as relações hierárquicas presentes nas salas de aula tradicionais.

Parece haver, potencialmente, uma carga subversiva nessas formulações, uma vez que elas recusam alguns dos pretensos "pilares" do edifício educativo, ou, pelo menos, parecem abalar alguns dos fundamentos da organização educativa convencional. Sob esses novos modelos, a situação ensino/aprendizagem se transforma numa relação onde todos os personagens podem alternar, constantemente, suas posições, sem que nenhum sujeito (ou, mais especialmente, sem que o/a professor/a) detenha, a priori, uma experiência, um saber ou uma autoridade mais do que os demais. Como consequência, há a expectativa de que a competição ceda lugar à cooperação, levando a uma produção do conhecimento coletiva, colaborativa, apoiada na experiência de todos/as (LOURO, 2007, p. 114).

Se a proposta de uma pedagogia feminista lembra alguns pontos da pedagogia de Paulo Freire, isso não é coincidência. No entanto, a autora aponta, também, algumas limitações das pedagogias feministas sem, contudo, condenar os seus esforços.

Com relação aos pensamentos de Paulo Freire, Scocuglia (2005) analisa as posições do autor no que tange a esse tempo pós-moderno. Freire, em seus escritos, destaca a importância da não domesticação 
do tempo e do papel interferente da subjetividade na história que, por si, já implica a requalificação do papel da educação. Uma das fases do pensamento de Paulo Freire corresponderia a uma fase pós-moderna, ou seja, uma série de posições pelas quais ele argumentou. Entretanto, Freire é incisivo ao rechaçar a pós-modernidade neoliberal e defender a pós-modernidade progressista e crítica.

Combatendo tanto a «esquerda» sectária, como a «direita oportunista», Freire conclama: "vamos ser pós-modernos: radical e utopicamente pós-modernos", na esperança de construção de uma sociedade que seja menos perversa, menos discriminatória, menos racista, menos machista que a sociedade que temos agora» (SCOCUGLIA, 2005, p. 41 , grifo do autor).

Nesse sentido, Louro (2007) afirma que, ao contrário daqueles/ as que associam as perspectivas pós-modernas ao abandono das causas coletivas, ao incitamento ao relativismo e à fragmentação, desmobilizadores e apolíticos, podemos ler, nessas perspectivas, um movimento oposto: o revigoramento e a ampliação do político. Certamente a concepção do político se transformou ao incorporar lutas e grupos sociais antes invisibilizados.

O colapso das 'narrativas grandiosas' foi visto por muitos observadores com medo, comoum conviteà situação de permissividade geral e a morte de toda ordem moral e social, o medo do vazio, a ausência de um padrão universalmente obrigatório, inequívoco e executável. "[...] o olho pós-moderno (isto é, o olho moderno liberto dos medos e inibições modernos) vê a diferença com alegria e prazer: a diferença é bela e não menos boa por isso" (BAUMAN, 1999, p. 269). As tentativas modernas de ordenação, ao observarem a ambivalência causada, por exemplo, pelas discussões de gênero e o questionamento de binarismos propostos pelos movimentos feministas, tenderam à assimilação (inicialmente) destas ambivalências, objetivando fundilas ao corpo nacional unificado e homogêneo. No entanto, como 
assevera Bauman (2011, p. 71), "[...] se tentassem forçar a mão [...] se tornariam suspeitos de desonestidade e intenções ignóbeis", e é o que vem transcorrendo-se no atual cenário educacional, como exemplo da Escola sem partido, propondo a supressão das discussões de gênero e demais propostas importantes ao nosso contexto líquido-moderno.

A tendência que se tornou comum há pouco tempo, de substituir as estratégias "fágicas" (assimilatórias), generalizadas na época da construção do Estado-nação, pelas "êmicas" (expulsionistas), a tendência à separação forçada, à rejeição dos imigrantes e à limpeza étnica, é uma admissão oblíqua e perversa de que esse é o caso que a ambivalência não pode ser resolvida nem superada (BAUMAN, 2011, p. 73).

Os tempos de pressão assimilatória parecem ter passado, mas a ambivalência tornou-se o pão de cada dia. Nesse sentido, a pós-modernidade (a modernidade em sua fase líquida) é a era do desencaixe sem o reencaixe.

O que esses estudos pretendem pôr em evidência diz respeito à mudança de paradigmas que buscam subverter muitos dos pilares da sociedade sólido-moderna, com seus dogmas e invenções sociais. Bauman (2000 apud ALMEIDA; GOMES; BRACHT, 2009) mostra que há a expressa esperança de que, mais cedo ou mais tarde, chegaremos ao entendimento sobre a pluralidade e a diversidade do mundo e de seus habitantes.

Conforme a interpretação que fazemos da análise de Bauman, é exatamente a "condição" pós-moderna ou a "sensibilidade" que ela engendra que nos fornece essa esperança. Para isso, seria importante deixar de lado todos os preconceitos e conclusões semânticas que esse termo suscitou e suscita ainda hoje e, com Bauman, passar a enxergá-lo como a possibilidade de um novo ponto de observação no interior da própria modernidade, capaz de permitir a reflexão sobre o projeto da ordem como tarefa e julgar sua (in)congruência, seus ganhos, perdas e os efeitos da turbulência que ele provocou. Ser um sociólogo da 
pós-modernidade, aliás, significa assumir essa perspectiva em relação à sociedade moderna, analisando-a criticamente, em vez de tomar o que precisa ser explicado como a própria explicação (tarefa que exatamente permite distinguir o sociólogo da pós-modernidade do sociólogo pós-moderno) (ALMEIDA; GOMES; BRACHT, 2009, p. 29-30).

Segundo análises dos/as autores/as, a pós-modernidade, pelo menos como ela aparece na obra de Bauman, torna-se um 'tempo' em que a modernidade tem condições de, finalmente, atingir sua maioridade, pois desconfia de tantas esperanças passadas que se tornaram pesadelos, libertando-se de velhas ilusões, emancipada e aberta ao inesperado, à contingência e à ambivalência. "Pósmodernidade é a modernidade que admite jogar dados, desde que esses não estejam de antemão viciados por algum legislador supremo" (ALMEIDA; GOMES; BRACHT, 2009, p. 29-30).

\section{Desafios da Educação na Modernidade Líquida}

Visualizamos, nestes tempos líquido-modernos, notáveis modificações no campo da educação, e no próprio significado do conhecimento e na sua forma de produção, distribuição, aquisição, assimilação e utilização. Nesse sentido, a educação precisa se alimentar não apenas de conhecimento, mas de pensamento crítico, capaz de subverter modelos hoje incapazes de dar conta de dialogar com o momento presente.

Este cenário de crise de fundamentação é derivado da crise inerente ao paradigma moderno. Lima (2010) supõe que se o cenário da crise atual não atinge os conteúdos da tradição pedagógica, mas as suas chances de sobrevivência histórica, fica instaurado o desafio de avaliarmos a produtividade mediadora da construção histórica herdada pela Pedagogia e também das novas contribuições e reflexões alcançadas pelas ciências da educação em relação às múltiplas 
problemáticas, que também não são estáveis, nem contínuas, mas que povoam os contextos escolares.

A educação ainda se encontra envolta nos grandes ideais das metanarrativas modernas, porém, como apresentado, percebemos que essas metanarrativas não sustentam com firmeza os pilares modernos, os quais estão abalados diante das transformações ocorridas na denominada Modernidade Líquida.

Em uma sociedade de consumidores/as instigados/as, forçados/as e induzidos/as pelo mercado do consumo, as chances de libertação dos ditames do mercado são mínimas, o que ocorre também na perspectiva da educação voltada para o mercado. Para pensar em outras possibilidades, é necessária a revolução cultural que questione esse sistema dominado pela 'ética' da privação, do individualismo alienado, da ganância e do lucro. Em uma sociedade dividida como a nossa entre os/as que têm e os/as que não têm, a cultura é o terreno onde se dá a luta pela manutenção ou superação das divisões sociais. "Nada menos que uma "revolução cultural" pode funcionar" (BAUMAN, 2013, p. 31).

Para Bauman (2013), embora os poderes do atual sistema educacional pareçam limitados, e ele próprio seja cada vez mais submetido ao jogo consumista, esse sistema ainda tem poderes de transformação suficientes para ser considerado um dos fatores promissores para essa revolução. Há um menosprezo desalentador com que se trata a escola. Entretanto, é pela escola que deveríamos recomeçar.

Em todas as épocas, o conhecimento foi avaliado com base em sua capacidade de representar fielmente o mundo. Mas como fazer quando o mundo muda de uma forma que desafia constantemente a verdade do saber existente, pegando de surpresa até os mais "bem-informados"? (BAUMAN, 2010, p. 43). 
O conhecimento produzido hoje é destinado a perseguir eternamente objetos sempre fugidios e que se dissolvem no momento em que são apreendidos. Issoé o contrário de tudo o que a aprendizagem e a educação representaram na maior parte de sua história. Segundo Bauman (2010), em nosso mundo volátil, de mudanças instantâneas e erráticas, os hábitos, esquemas e preferências sólidos e estáveis, objetos da educação ortodoxa, transformam-se em desvantagens.

O grande problema, para o autor, é que uma reforma das estratégias educacionais, por mais brilhante e ampla que seja, pode muito pouco ou quase nada nesse caso, pois foi o mundo fora da escola que mudou muito em relação ao tipo de mundo para o qual as escolas estão formando. No passado, a educação assumia muitas formas e adaptava-se às circunstâncias mutáveis. Entretanto, as mudanças presentes são diferentes e pressupõem desafios nunca antes enfrentados. "A arte de viver num mundo hipersaturado de informação ainda não foi apreendida. E o mesmo vale também para a arte ainda mais difícil de preparar os homens para esse tipo de vida" (BAUMAN, 2010, p. 60).

Para o autor, o "mundo da escola" deve se vincular cada vez mais ao "mundo da vida", derrubando muros e se inserindo num contexto humano ampliado de formação pessoal e de grupo. Com esse mundo saturado de informações, é preciso que se criem consciências críticas, cientes de que a educação está também nas mídias, nos movimentos sociais, nos espaços públicos de encontro da diversidade, dilatando a perspectiva da educação.

Precisamos urgentemente de novos conceitos para acomodar e organizar nossas experiências. A esperança é uma atitude possível diante de tais crises. Um autor que trabalha com uma mudança de perspectiva, na esperança e na crença de que novos sentidos e significados possam ser construídos, é Boaventura Sousa Santos (2007). Ele fala da epistemologia do conhecimento-emancipação, entretanto, 
esse conhecimento depende do avanço das lutas sociais contra a opressão, a discriminação e a exclusão social. Essa epistemologia aponta para novos modos de produção do conhecimento.

Defino-os, em geral, como epistemologias do Sul, entendendo por Sul a metáfora do sofrimento humano, sistematicamente causado pelo capitalismo. Trata-se, pois, de um Sul não imperial (porque há um Sul imperial, que reproduz no Sul os interesses do Norte) que resiste contra a opressão, a exploração e a exclusão (SANTOS, 2007, p. 4).

Para o autor, há muitos tipos de verdade e devemos nos perguntar por que razão, em relação a alguns deles, não temos qualquer dúvida. A verdade é a sucessão de verdades com que vamos intervindo eficazmente no mundo. Os limites dessa eficácia são os limites da verdade. E é por isso que hoje, rodeada por crises, nossa sociedade está à beira de um colapso, pois suas verdades não mais alcançam esse mundo hipersaturado de informações. Sendo assim, é imperativo iniciar um diálogo e uma tradução intercultural entre os diferentes conhecimentos e práticas: sulcêntricos e nortecêntricos, populares e científicos, femininos e masculinos, urbanos e rurais, dentre outros.

Nessa perspectiva,

[...] a ignorância leva à paralisia da vontade. Quem não sabe o que guarda no depósito, não tem como calcular os riscos. [...] a dominação através da ignorância e da incerteza deliberadamente cultivadas é mais aceitável e menos cansativa do que o princípio baseado na discussão atenta dos acontecimentos e no esforço demorado de estabelecer a verdade dos fatos e os modos menos arriscados de proceder. A ignorância política entrançada com a inatividade fica ao alcance da mão cada vez que é sufocada a voz da democracia ou as suas mãos ficam atadas. É preciso uma educação permanente para dar a nós mesmos a possibilidade de escolher. Mas temos ainda mais necessidade de salvar as condições que tornam as escolhas possíveis ao nosso alcance (BAUMAN, 2009, p. 682). 
Tomando como referência os escritos de Paulo Ghiraldelli Junior (2000) em seu livro Didática e teorias educacionais, os/as educadores/as pós-modernos/as já não podem ser vistos/as como não alinhados/as com a luta por um mundo melhor. Ao contrário, o mundo em cuja construção estão empenhados é melhor do que aquele que os/ as marxistas desejaram, pois almejam, além da justiça social, também a liberdade para todos/as e querem que a teoria educacional ajude os/ as estudantes a serem simplesmente felizes. Bauman (2015) acredita que para que a escola e a educação façam sentido é preciso que estas consigam efetivamente produzir nos/as alunos/as a capacidade de pensamento crítico, e não a mera recepção de informações, que nesse contexto, vem em montanhas de diferentes direções.

Para confrontar sua condição existencial e enfrentar seus desafios, a humanidade precisa se colocar acima dos dados da experiência a que tem acesso enquanto indivíduos. Ou seja, a percepção individual, para ser ampliada, necessita da assistência de intérpretes munidos com dados não amplamente disponíveis à experiência individual. E a sociologia, enquanto parte integrante desse processo interpretativo -um processo em andamento e permanentemente inconclusivo-, constitui um empenho constante para ampliar os horizontes cognitivos dos indivíduos e uma voz potencialmente poderosa nesse diálogo sem fim com a condição humana (BAUMAN, 2003, p. 31).

A profundidade e a amplitude das problemáticas educacionais na Modernidade Líquida nos colocam o desafio de repensarmos nossas práticas educacionais, no sentido de superar as constantes crises que a educação institucionalizada vem enfrentando. Com novo modo de pensar, teóricos/as da pós-modernidade colocam em xeque antigas produções discursivas a respeito da educação. Concordando ou não com as diversas produções críticas e póscríticas na academia, precisamos entender que há a necessidade do rompimento com pensamentos que acreditam em conhecimentos 
universalizantes e totalitários. A ambivalência nos conhecimentos, nas relações humanas, nos sentimentos humanos é consequência dos tempos líquido-modernos. Assim, precisamos instigar o pensamento e a prática numa perspectiva que supere as atuais contradições dos sistemas educacionais, na esperança e convicção de que a mudança é possível e que a luta por uma genuína revolução cultural precisa ser gestada/construída com base no entendimento sobre a pluralidade e a diversidade do mundo e de seus habitantes, superando as exclusões, desigualdades e distopias sociais.

\section{REFERÊNCIAS}

ALMEIDA, Felipe Quintão; GOMES, Ivan Marcelo; BRACHT, Valter. Bauman e educação. Belo Horizonte: Autêntica, 2009.

BAUMAN, Zygmunt. A sociedade líquida: entrevistado por Maria Lúcia Garcia Palhares-Burke. São Paulo: Folha de São Paulo, 2003. Disponível em: <http:// www.prefeitura.sp.gov.br/cidade/secretarias/upload/chamadas/4_Encontro_ Entrevista_A_Sociedade_Liquida_1263224949.pdf $\geq$. Acesso em: fev. 2016.

. Bauman sobre Bauman. Rio de Janeiro: Zahar, 2011.

. Capitalismo parasitário: e outros temas contemporâneos. Rio de Janeiro:

Zahar, 2010.

. Desafios pedagógicos e modernidade líquida: entrevista de Alba

Porcheddu sobre a educação. Cadernos de Pesquisa, São Paulo, v. 39, n. 137, p. 661684, maio/ago. 2009.

. Ética pós-moderna. São Paulo: Paulus, 1997.

. Modernidade e ambivalência. Rio de Janeiro: Zahar, 1999.

. Modernidade líquida. Rio de Janeiro: Zahar, 2001.

. Observatório da imprensa entrevista o sociólogo Zygmunt Bauman. 2015.

Disponível em: <https://www.youtube.com/watch?v=kM5p8DqgG80>. Acesso em: 3 ago. 2016.

Zahar, 2013.

. Sobre educação e juventude: conversas com Ricardo Mazzeo. Rio de Janeiro: 
FRANÇA, Rafael Marques. Crises e emergências paradigmáticas na ciência, no currículo e na educação física. 2009. Dissertação (Mestrado em Educação) - Programa de Pós-Graduação em Educação, Universidade Estadual de Londrina, Centro de Educação, Comunicação e Artes, Londrina, 2009.

GHIRALDELLI JUNIOR, Paulo. As teorias educacionais e as didáticas na modernidade e pós-modernidade. . Didática e teorias educacionais. Rio de Janeiro: DP\&A, 2000, p. 39-75.

GOERGEN, Pedro. O embate modernidade/pós-modernidade e seu impacto sobre a teoria e a prática educacionais. Eccos Revista Científica, São Paulo, n. 28, p. 149-169, maio/ago. 2012.

HARVEY, David. Condição pós-moderna: uma pesquisa sobre as origens da mudança cultural. 22. ed. São Paulo: Edições Loyola Jesuítas, 2012.

HUTCHEON, Linda. A incredulidade a respeito das metanarrativas: articulando pós-modernismo e feminismos. Labrys: Estudos Feministas, [S. 1.], n. 1-2, p. 1-5, dez. 2002.

LIBANEO, José Carlos. As teorias pedagógicas modernas resignificadas pelo debate contemporâneo na educação. In: LIBÂNEO, José Carlos; SANTOS, Akiko (Org.). Educação na era do conhecimento em rede e transdisciplinaridade. São Paulo: Alínea, 2005. Disponível em: <http://www.ia.ufrrj.br/ppgea/conteudo/T1SF/ Akiko/03.pdf $>$. Acesso em: 20 mar. 2014.

LIMA, João Francisco Lopes. A pedagogia e o cenário pós-moderno: sobre as possibilidades de continuar educando. Educere et Educare: Revista de Educação, Cascavel, v. 5, n. 10, p. 1-12, 2010.

LOURO, Guacira Lopes. Gênero, sexualidade e educação: uma perspectiva pósestruturalista. Petrópolis: Vozes, 2007.

LYOTARD, Jean-François. O pós-moderno. 3. ed. Rio de Janeiro: José Olympio Editora, 1988.

McLAREN, Peter. Pós-modernismo, pós-colonialismo e pedagogia. In: SILVA, Tomaz Tadeu da. Teoria crítica em tempos pós-modernos. Porto Alegre: Artes Medicas, 1993. p. 9-40.

MOREIRA, Antonio Flavio; TADEU, Tomaz (Org.). Currículo, cultura e sociedade. 12. ed. São Paulo: Cortez, 2011.

MORIN, Edgar. O paradigma perdido: a natureza humana. Portugal: Publicações Europa América, 1988. 
PONDÉ, Luiz Felipe. A invenção do contemporâneo: o diagnóstico de Zygmunt Bauman para a pós-modernidade. Campinas: CPLF Cultura, 2011. Disponível em: <https://www.youtube.com/watch?v=58MMs5j3TjA>. Acesso em: 20 mar. 2014.

SANTOS, Boaventura Sousa. Em torno de um novo paradigma sócioepistemológico: Manuel Tavares conversa com Boaventura de Sousa Santos. Revista Lusófona de Educação, Lisboa, v. 10, n. 10, p. 1-11, 2007.

SCOCUGLIA, Afonso Celso. Paulo Freire e a «conscientização» na transição pósmoderna. Educação, Sociedade \& Culturas, Porto, n. 23, p. 21-42, 2005.

SILVA, Tomaz Tadeu. Documentos de identidade: uma introdução às teorias do currículo. Belo Horizonte: Autêntica, 2011. 